\section{Repurposing pyridoxamine for therapeutic intervention of intravascular cell-cell interactions in mouse models of sickle cell disease}

\author{
Jing Li,${ }^{1 *}$ Si-Yeon Jeong, ${ }^{1 *}$ Bei Xiong,,${ }^{1,2^{*}}$ Alan Tseng, ${ }^{1}$ Andrew B. Mahon, ${ }^{3}$
} Steven Isaacman, ${ }^{3}$ Victor R. Gordeuk ${ }^{4,5}$ and Jaehyung $\mathrm{Cho}^{1}$

${ }^{1}$ Department of Pharmacology, University of Illinois at Chicago College of Medicine, Chicago, IL, USA; ' Department of Hematology, Zhongnan Hospital of Wuhan University, Wuhan, Hubei, P.R. China; ${ }^{3}$ PHD Biosciences, New York, NY, USA; ${ }^{4}$ Section of Hematology/Oncology, University of Illinois at Chicago College of Medicine, Chicago, IL, USA and ${ }^{5}$ Comprehensive Sickle Cell Center, University of Illinois at Chicago College of Medicine, Chicago, IL, USA

*Jing Li, Si-yeon Jeong, and Bei Xiong contributed equally as co-first authors.

\section{ABSTRACT}

$\Lambda$ dherent neutrophils on vascular endothelium positively contribute to cell-cell aggregation and vaso-occlusion in sickle cell disease (SCD). In the present study, we demonstrated that pyridoxamine, a derivative of vitamin $\mathrm{B} 6$, might be a therapeutic agent to alleviate intravascular cell-cell aggregation in SCD. Using real-time intravital microscopy, we found that one oral administration of pyridoxamine, in a dose-dependent manner, increased the rolling influx of neutrophils and reduced neutrophil adhesion to endothelial cells in cremaster microvessels of SCD mice challenged with hypoxia-reoxygenation. Short-term treatment also mitigated neutrophil-endothelial cell and neutrophil-platelet interactions in the microvessels and improved the survival of SCD mice challenged with tumor necrosis factor- $\alpha$. The inhibitory effects of pyridoxamine on intravascular cell-cell interactions were enhanced by co-treatment with hydroxyurea. We observed that long-term (5.5 months) oral treatment with pyridoxamine significantly reduced the adhesive function of neutrophils and platelets, and down-regulated the expression of E-selectin and intercellular adhesion molecule-1 on the vascular endothelium in tumor necrosis factor- $\alpha$-challenged SCD mice. Ex vivo studies revealed that the surface amount of $\alpha \mathrm{M} \beta 2$ integrin was significantly decreased in stimulated neutrophils isolated from SCD mice treated with pyridoxamine-containing water. Studies using platelets and neutrophils from SCD mice and patients suggested that treatment with pyridoxamine reduced the activation state of platelets and neutrophils. These results suggest that pyridoxamine may be a novel therapeutic and a supplement to hydroxyurea to prevent and treat vaco-occlusion events in SCD.

\section{Introduction}

Sickle cell disease (SCD) is an inherited autosomal recessive disorder caused by a Glu6Val mutation in $\beta$-globin, resulting in hemolysis of red blood cells (RBC), oxidative stress, and chronic inflammation. ${ }^{1}$ Recurrent vaso-occlusion (VOC) is the hallmark of SCD and is mediated by intravascular cell-cell adhesion and aggregation. VOC is a crucial trigger for severe pain crisis and acute chest syndrome, a common complication and cause of death in SCD patients. ${ }^{1,2}$ Hydroxyurea (HU) and L-glutamine are the only US Food and Drug Administration-approved medications for treating SCD. However, SCD patients undergoing HU therapy still suffer from VOC-mediated events, and $25-50 \%$ of patients do not respond to this drug with an adequate increase in fetal hemoglobin ( $\mathrm{HbF}){ }^{3,4} \mathrm{~A}$ recent phase III study has shown that, compared to the placebo control, treatment with L-glutamine reduces the number of pain crises in SCD patients. ${ }^{5}$ In this trial, however, patients on both
Ferrata Storti Foundation
Haematologica 2020
Volume 105(10):2407-2419

\section{Correspondence:}

JAEHYUNG CHO

thromres@uic.edu

Received: May 15, 2019.

Accepted: October 29, 2019.

Pre-published: October 31, 2019.

doi:10.3324/haematol.2019.226720

(C)2020 Ferrata Storti Foundation

Material published in Haematologica is covered by copyright. All rights are reserved to the Ferrata Storti Foundation. Use of published material is allowed under the following terms and conditions:

https://creativecommons.org/licenses/by-nc/4.0/legalcode. Copies of published material are allowed for personal or internal use. Sharing published material for non-commercial purposes is subject to the following conditions: https://creativecommons.org/licenses/by-nc/4.0/legalcode, sect. 3. Reproducing and sharing published material for commercial purposes is not allowed without permission in writing from the publisher. 
L-glutamine therapy and HU still experienced pain crises, and this underscores the need for new therapies for SCD.

Adherent neutrophils on endothelial cells (EC) are a key contributor to cell-cell aggregation and VOC in SCD. ${ }^{6-8}$ Clinical studies with crizanlizumab (a blocking antibody against P-selectin) demonstrated that inhibition of leukocyte-EC interactions prevents vaso-occlusive pain crises in SCD patients. ${ }^{9,10}$ Nevertheless, complete blockade of leukocyte-EC contact might impair the immune response. Because of the contribution of activated platelets to cellcell aggregation and VOC, antiplatelet drugs including P2Y12 antagonists (e.g. prasugrel and ticagrelor) have been tested in clinical trials for the treatment of VOC in SCD patients. A phase III study, however, revealed that prasugrel does not decrease the rate of VOC-mediated pain crises in children and adolescents with SCD. ${ }^{11}$ Furthermore, antiplatelet drugs increase the risk of major bleeding. ${ }^{12}$ Thus, there remains a need for safer and more efficacious therapeutics that ameliorate intravascular cell-cell aggregation and VOC-mediated conditions in SCD.

Pyridoxamine, a derivative of vitamin B6, scavenges reactive oxygen species (ROS) and toxic carbonyls and inhibits the formation of advanced glycation end products (AGE). ${ }^{13,14}$ Preclinical studies suggest that long-term treatment with pyridoxamine inhibits the progression of renal disease and hyperlipidemia in diabetic rats ${ }^{15}$ and reduces adherence of uropathogenic E. coli to the bladder in diabetic mice. ${ }^{16}$ Furthermore, a phase II study demonstrated that oral administration of pyridoxamine has benefits for creatinine clearance and the level of urinary transforming growth factor- $\beta 1$ (TGF- $\beta 1$ ) in patients with type 1 and type 2 diabetic nephropathy. ${ }^{17}$ In contrast, another clinical study did not show any benefit of pyridoxamine treatment on serum creatinine concentration in patients with type 2 diabetic nephropathy after 1 year of therapy. ${ }^{18}$ No or minimal adverse events of pyridoxamine were observed in clinical studies. ${ }^{17,18}$ Intriguingly, the plasma concentration of AGE is elevated under oxidative stress conditions and is associated with organ complications in SCD patients. ${ }^{19}$

We therefore tested the effect of pyridoxamine on intravascular cell-cell interactions and VOC in SCD. We found that short- and long-term oral administration of pyridoxamine reduces neutrophil recruitment to the cremaster venular wall of SCD mice challenged with hypoxia/reoxygenation (H/R) or tumor necrosis factor- $\alpha$ (TNF- $\alpha$ ) and improved survival. The beneficial effects of pyridoxamine were enhanced when HU was co-administered to SCD mice. We observed that pyridoxamine reduced the activation state and/or adhesiveness of neutrophils, platelets, and EC in SCD mice without affecting the plasma levels of AGE and nitric oxide (NO). These results suggest that pyridoxamine could be beneficial as a stand-alone therapeutic agent and in combination with $\mathrm{HU}$ to prevent and treat VOC-mediated events in SCD patients.

\section{Methods}

The University of Illinois Institutional Animal Care and Use Committee approved all animal care and experimental procedures. All patients enrolled in this study provided informed consent. The collection and use of blood samples for laboratory analysis were approved by the Institutional Review Board of the University of Illinois at Chicago.

\section{In vivo intravital microscopy}

Intravital microscopy was performed as previously described. ${ }^{20,21}$ For short-term treatment, pyridoxamine was given to SCD mice 3 hours (h) before in vivo imaging, given a previous report showing that the half-life of pyridoxamine is around $1.5 \mathrm{~h}$ in rats after oral administration. ${ }^{15}$ SCD mice were placed into a hypoxic chamber $\left(8 \% \mathrm{O}_{2}\right)$ for $3 \mathrm{~h}$, followed by oral administration of vehicle (saline) or different doses of pyridoxamine (10-100 mg/kg BW). After $3 \mathrm{~h}$ of reoxygenation at room temperature, mice were anesthetized with ketamine and xylazine, and the cremaster muscle was exposed for intravital microscopy. In some experiments, vehicle or pyridoxamine was given orally to SCD mice before intraperitoneal (ip) injection of TNF- $\alpha$ (500 ng). Three hours after TNF- $\alpha$ injection, mice underwent intravital microscopy.

To assess the effect of long-term treatment with pyridoxamine, mice were given acidic water ( $\mathrm{pH} 4.0$ ) with or without pyridoxamine $(2 \mathrm{~g} / \mathrm{L})$ for 5.5 months as previously described, ${ }^{15,22}$ starting at 2 weeks after bone marrow transplantation (BMT). Body weight and complete blood counts were measured every other week. After 5.5-months of treatment, the mice were challenged with $\mathrm{H} / \mathrm{R}$ or ip injection of TNF- $\alpha$ as described above. Platelets and neutrophils were monitored by infusion of DyLight 488-conjugated anti-CD42c $(0.1 \mu \mathrm{g} / \mathrm{g} \mathrm{BW})$ and Alexa Fluor 647-conjugated anti-Ly-6G antibodies $(0.1 \mu \mathrm{g} / \mathrm{g}$ BW), respectively, through a jugular cannula. Fluorescence and bright-field images were recorded using an Olympus BX61W microscope with a 60x1.0 NA water immersion objective lens and a high-speed camera (ORCAFlash4.0 V3, C13440-20CU, Hamamatsu). Data were analyzed using SlideBook 6 (Intelligent Imaging Innovations). Since the cremaster venules with a diameter of $<10 \mu \mathrm{m}$ were mostly occluded, as assessed by absence of circulating RBC, the dynamics of intravascular cell-cell adhesion/accumulation were monitored in the venules with a diameter of $25-40 \mu \mathrm{m}$. Five to eight vessels were randomly chosen in each mouse. The numbers of rolling (cells per minute) and adherent neutrophils (cells per 5 minutes) were counted in the field of view $(221.45 \mu \mathrm{m} \times 221.45 \mu \mathrm{m})$. The rolling velocity of neutrophils was also measured. Time " 0 " was set as the image capture was initiated at each vessel. To determine the kinetics of platelet accumulation, the integrated median fluorescence intensity values of the anti-CD42c antibody were normalized to the number of adherent neutrophils and the length of vessels, and plotted as a function of time. The experiments were performed in a single-blind fashion in which the investigators did not know the treatment allocation of the mice.

Further details of the methods used are provided in the Online Supplementary Appendix.

\section{Statistical analysis}

Data were analyzed using GraphPad Prism 7 by Student's $t$-test, Mann-Whitney U test, ANOVA with Dunnett's or Tukey's test, Kruskal-Wallis test with post-hoc Dunn correction, and MantleCox log-rank test (survival curve). $P<0.05$ was considered statistically significant.

\section{Results}

One oral administration of pyridoxamine reduces neutrophil-endothelial cell interactions in the cremaster venules of sickle cell disease mice challenged with hypoxia/reoxygenation

Red blood cell sickling under hypoxic conditions leads to hemolysis, cell-cell aggregation, and VOC in SCD patients. ${ }^{23}$ Similarly, $\mathrm{H}$ challenge results in RBC sickling and sickle hemoglobin ( $\mathrm{HbS})$ polymerization in Berkeley 
mice, and subsequent $\mathrm{R}$ conditions induce acute VOC events. ${ }^{20,24}$ We and others have demonstrated that adherent neutrophils on activated EC support adhesion of other blood cells, including sickle RBC and platelets, ${ }^{6,20,25,26}$ and that $\mathrm{H} / \mathrm{R}$ challenge induces intravascular cell-cell interactions and VOC events in SCD mice. ${ }^{20,27}$ To test the effect of short-term treatment with pyridoxamine on cell-cell interactions in SCD, different doses of pyridoxamine (10-100 $\mathrm{mg} / \mathrm{kg} \mathrm{BW}$ ) were given orally to SCD mice after $\mathrm{H}$ challenge $\left(8 \% \mathrm{O}_{2}\right.$ for $3 \mathrm{~h}$ ), followed by $\mathrm{R}$ (at room temperature for another $3 \mathrm{~h}$ ) (Figure 1A). Using intravital microscopy, we found that compared to the vehicle control, pyridoxamine, in a dose-dependent manner, enhanced the rolling influx of neutrophils and decreased neutrophil adhesion to EC in H/R-challenged SCD mice (Figure 1B-D and Online Supplementary Videos 1-4). Pyridoxamine at the highest
A

B

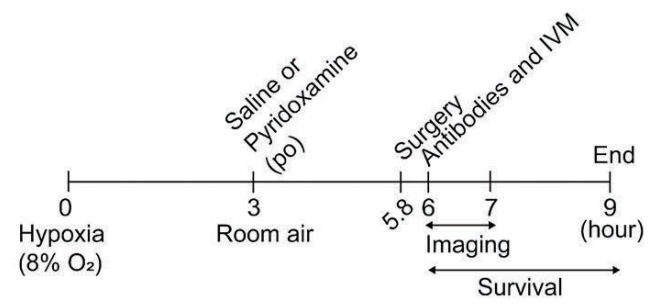

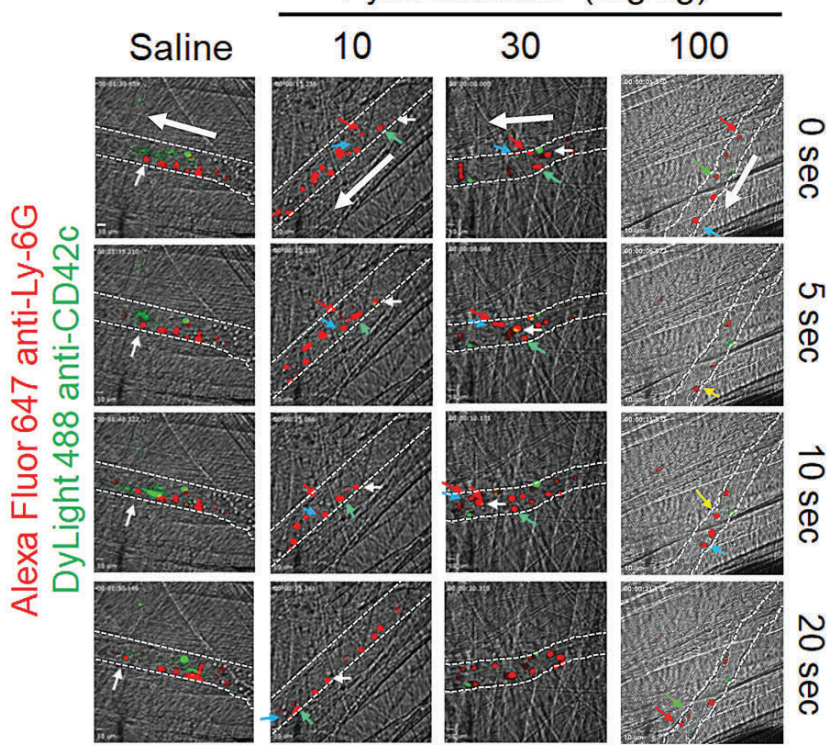

C

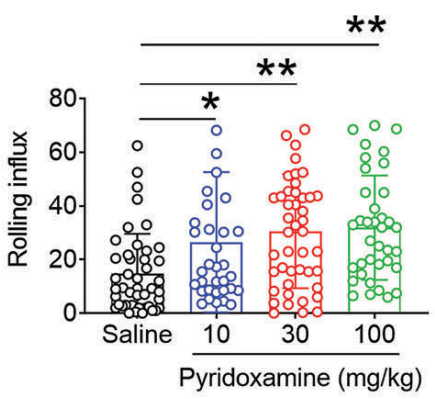

$\mathrm{F}$

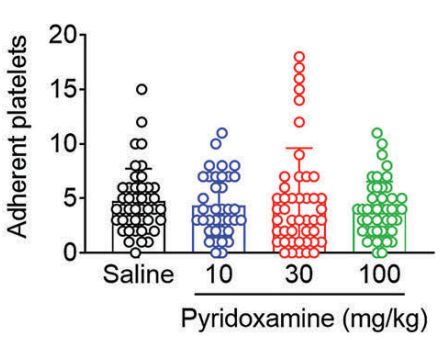

D

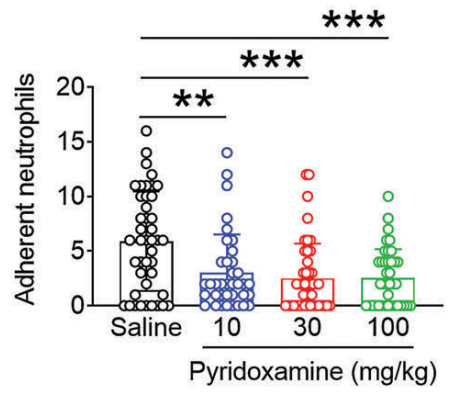

G

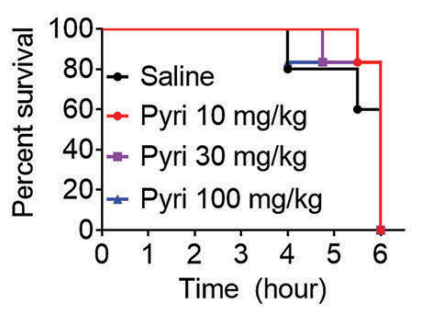

E

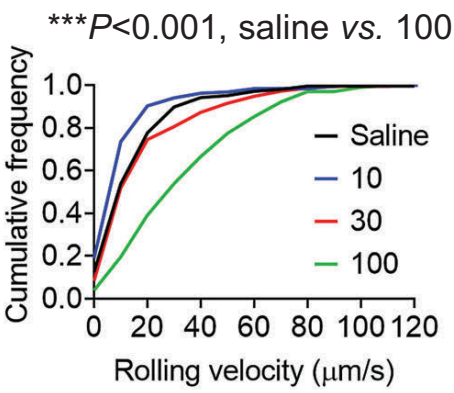

Figure 1. A single oral administration of pyridoxamine inhibits neutrophil-endothelial cell (EC) interactions in the cremaster venules of hypoxia/reoxygenation $(\mathrm{H} / \mathrm{R})$-challenged sickle cell disease $(\mathrm{SCD})$ mice. SCD mice were placed into a hypoxic chamber $\left(8 \% \mathrm{O}_{2}\right)$ for 3 hours $(\mathrm{h})$ and treated with oral administration of vehicle or different doses of pyridoxamine (10,30 or $100 \mathrm{mg} / \mathrm{kg} \mathrm{BW})$. After reoxygenation, intravital microscopy was performed as described in the Methods section. Neutrophils (red) and platelets (green) were visualized by infusion of Alexa Fluor 647-conjugated anti-Ly-6G and DyLight 488-conjugated anti-CD42C antibodies, respectively. (A) Timeline for $\mathrm{H} / \mathrm{R}$ challenge, pyridoxamine treatment, surgery, in vivo imaging, and recording survival times. (B) Representative images. Time "O" was set as when image capture began on each vessel. White dotted lines indicate the vessel wall; large arrows indicate direction of blood flow. Different colored smal arrows indicate individual rolling neutrophils over 20 seconds. Bar $=10 \mu \mathrm{m}$. (C and D) The number of rolling and adherent neutrophils. (E) Cumulative frequency of the rolling velocity of neutrophils. (F) Number of platelets adherent to neutrophils and $E C$ was counted. Data represent the mean \pm standard deviation $(S D)$ ( $n=36-45$ venules in 6-7 mice per group). (G) Survival curves of SCD mice during or after intravital microscopy. $* P<0.05$, $* * P<0.01$, and $* * * P<0.001$ versus vehicle control, ANOVA with Tukey's test (C and D) and Kruskal-Wallis test with post-hoc Dunn correction (E). 
A

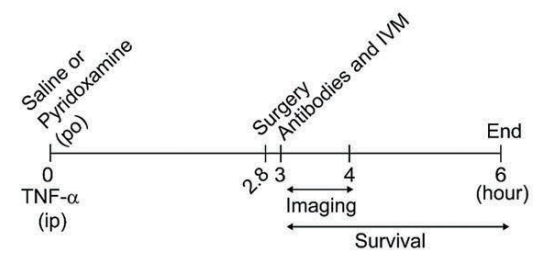

B
C

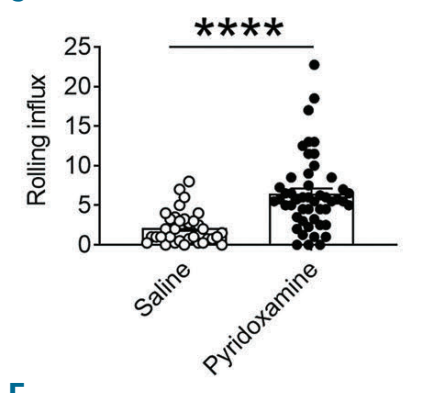

E

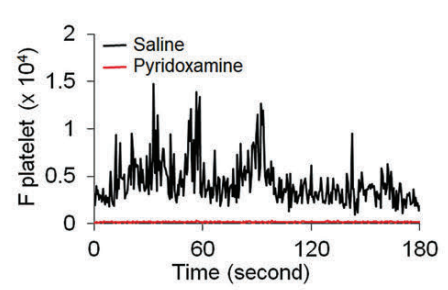

D

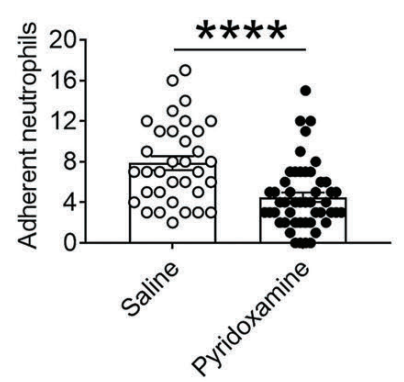

F

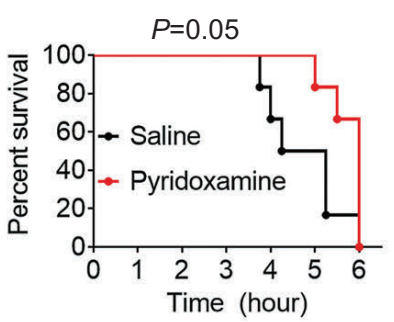

Figure 2. A single oral administration of pyridoxamine reduces intravascular cell-cell interactions in the cremaster venules of tumor necrosis factor (TNF)- $\alpha$-challenged sickle cell disease (SCD) mice and improves their survival. SCD mice were treated with oral administration of vehicle or pyridoxamine (100 mg/kg BW) before intraperitoneal injection of TNF- $\alpha$. Three hours later, intravital microscopy was performed as described in Figure 1. (A) Timeline for pyridoxamine treatment, TNF- $\alpha$ injection, imaging, and recording survival times in SCD mice. (B) Representative images. Neutrophils and platelets are shown in red and green, respectively. Time " 0 " was set as when image capture began on each vessel. Large arrows indicate direction of blood flow; different colored small arrows indicate individual rolling neutrophils over 30 seconds. Bar $=10 \mu \mathrm{m}$. (C and D) The number of rolling and adherent neutrophils. (E) Integrated median fluorescence intensity values of anti-CD42c antibodies ( $F$ platelets) were plotted over time. Data represent the mean \pm standard deviation ( $n=33-47$ venules in 6 mice per group). (F) Survival curves of SCD mice during or after intravital microscopy. $* * * * P<0.0001$ versus vehicle control, Student's $t$-test (C and D) and Mantel-Cox log-rank test (F).

dose $(100 \mathrm{mg} / \mathrm{kg} \mathrm{BW})$ markedly enhanced the cumulative frequency of the rolling velocity of neutrophils $\left({ }^{* *} P<0.001\right.$ vs. saline) (Figure $\left.1 \mathrm{E}\right)$. Platelets adhered to both neutrophils and EC in the microvessels of H/R-challenged SCD mice, and pyridoxamine treatment did not affect the number of adherent platelets (Figure 1F). Most SCD mice in all groups survived for the duration of the study (Figure 1G). Since aged neutrophils, defined by upregulated CXCR4/ $\alpha \mathrm{M} \beta 2$ and down-regulated L-selectin on the surface, positively contribute to inflammatory conditions in SCD ${ }^{8}$ we tested whether pyridoxamine affects neutrophil aging in SCD mice. As assessed by CXCR4 ${ }^{\text {high }}$ and L-selectin ${ }^{\text {low }}$ in flow cytometry, the percentage of aged neutrophils was maximal around $3 \mathrm{pm}$ with a 14-hour light and 10-hour dark cycle, and one oral administration of pyridoxamine (100 mg/kg BW) had no significant effect on neutrophil aging (Online Supplementary Figure S1). These results indicate that a single oral administration of pyridoxamine attenuates neutrophil-EC interactions in the microvessels of H/R-challenged SCD mice without affecting neutrophil aging.

\section{One oral administration of pyridoxamine reduces interactions of neutrophils with endothelial cells and platelets in the venules of sickle cell disease mice challenged with tumor necrosis factor- $\alpha$ and improves survival}

We have demonstrated that blocking neutrophil-EC and neutrophil-platelet interactions mitigates acute VOC events in microvessels and improves the survival of
TNF- $\alpha$-challenged SCD mice..$^{20,21,28}$ Compared to H/Rchallenge, TNF- $\alpha$ challenge in SCD mice induces a more severe inflammatory condition under which most neutrophils stably adhere to the vessel wall, supporting platelet adhesion. ${ }^{20}$ Thus, we use the TNF- $\alpha$ model to assess the effect of pyridoxamine on neutrophil rolling and adhesion and neutrophil-platelet interactions (Figure 2A). Compared to the vehicle control, a single oral administration of pyridoxamine $(100 \mathrm{mg} / \mathrm{kg} \mathrm{BW})$ significantly increased the rolling influx of neutrophils and reduced the number of adherent neutrophils on the inflamed EC (Figure 2B-D and Online Supplementary Videos 5 and 6). Platelets mainly attached to adherent neutrophils but not inflamed EC in TNF- $\alpha$-challenged SCD mice, and pyridoxamine treatment inhibited adhesion and accumulation of platelets on adherent neutrophils as assessed by the fluorescence intensity of an anti-CD42c antibody (Figure 2E). Importantly, survival times for TNF- $\alpha$-challenged SCD mice were prolonged after a single oral administration of pyridoxamine, compared to the control $(P=0.05)$ (Figure $2 F)$. Median survival time for mice treated with vehicle and pyridoxamine was 4.7 and $6 \mathrm{~h}$ after TNF- $\alpha$ injection, respectively. No beneficial effects were observed when $30 \mathrm{mg} / \mathrm{kg}$ BW of pyridoxamine was administered orally (data not shown). These results suggest that a single oral administration of pyridoxamine effectively mitigates neutrophil-EC and neutrophil-platelet interactions in microvessels and improves the survival of SCD mice under severe inflammatory conditions. 
Co-treatment with hydroxyurea enhances the inhibitory effect of pyridoxamine on neutrophil rolling and adhesion in the venules of tumor necrosis factor- $\alpha$-challenged sickle cell disease mice

We reported that intravenous and oral administration of $\mathrm{HU}$ and an AKT inhibitor, compared to each drug alone, has immediate benefits for acute VOC events and the survival of TNF- $\alpha$-challenged SCD mice. ${ }^{20,28,29}$ Therefore, we sought to test whether co-administration of $\mathrm{HU}$ and pyridoxamine potentiates the inhibitory effect on intravascular cell-cell interactions in SCD. Since a single oral administration $(250 \mathrm{mg} / \mathrm{kg} \mathrm{BW})$ of HU reduces leukocyte adhesion to the venular wall of SCD mice, ${ }^{28,30}$ we tested the combined effect of $250 \mathrm{mg} / \mathrm{kg} \mathrm{BW}$ of $\mathrm{HU}$ and $100 \mathrm{mg} / \mathrm{kg}$ BW of pyridoxamine in TNF- $\alpha$-challenged SCD mice (Figure 3A). Compared to vehicle or HU alone, pyridoxamine or the combination of both treatments increased the rolling influx of neutrophils on the venules of SCD mice (Figure 3B). In contrast, the rolling velocity of neutrophils was faster in the groups treated with $\mathrm{HU}$ alone or both $\mathrm{HU}$ and pyridoxamine than those treated with vehicle or pyridoxamine alone (Figure $3 \mathrm{C}$ ). These results suggest that pyridoxamine and $\mathrm{HU}$ are likely to inhibit neutrophil rolling on EC through distinct mechanisms. Treatment with either HU or pyridoxamine significantly reduced neutrophil adhesion to the vessel wall, and the inhibitory effect was enhanced when both were administered (Figure 3D). We found that platelet-neutrophil interactions were abrogated by treatment with each drug or in combination, compared to the vehicle control (Figure 3E). Furthermore, compared to the vehicle control, treatment with HU, pyridoxamine, or both significantly improved the survival of TNF- $\alpha$-challenged SCD mice (Figure 3F). Median survival time for mice treated with vehicle, HU, pyridoxamine, and both drugs was 4.4, 5.6, 5.8, and $6 \mathrm{~h}$ after TNF- $\alpha$ injection, respectively.

The interactions between EC E-selectin and neutrophil receptors initiate neutrophil rolling, whereas binding of neutrophil $\beta 2$ integrins, such as $\alpha \mathrm{L} \beta 2$ and $\alpha \mathrm{M} \beta 2$, to EC ICAM-1 results in stable neutrophil adhesion and crawling during vascular inflammation. ${ }^{31}$ Therefore, we determined whether HU and pyridoxamine affect the expression of these molecules on the vessel wall of cremaster muscles taken from the SCD mice after intravital microscopy. We found that compared to the vehicle control, short-term treatment with $\mathrm{HU}$ alone or both $\mathrm{HU}$ and pyridoxamine, but not pyridoxamine alone, significantly decreased the expression of E-selectin (Figure 3G-I). ICAM-1 expression was further reduced in SCD mice treated with both drugs, compared to HU or pyridoxamine alone. Since the increased levels of soluble EC-derived adhesion molecules, including selectins and ICAM-1, are associated with organ dysfunction and mortality in SCD patients, ${ }^{32}$ we also measured the plasma levels of soluble E-selectin and ICAM-1. Oral administration of pyridoxamine or both $\mathrm{HU}$ and pyridoxamine significantly reduced the level of soluble ICAM-1 but not E-selectin in SCD mice (Figure 3J and $\mathrm{K})$. Treatment with HU alone had no inhibitory effect, as reported previously. ${ }^{33}$ In addition, we evaluated the plasma levels of inflammatory cytokines, IL-1 $\beta$ and IL-6. We found that HU or pyridoxamine alone, or the combination of the two markedly decreased the level of IL-1 $\beta$ but not IL-6 (Figure 3L and M), supporting the anti-inflammatory effect of each drug. These results suggest that the combination of pyridoxamine and $\mathrm{HU}$ has synergistic effects in reducing neutrophil-EC interactions in TNF- $\alpha$ challenged SCD mice.

\section{Long-term treatment with pyridoxamine attenuates neutrophil-endothelial cell interactions in the venules of tumor necrosis factor- $\alpha$-orhypoxia/ \\ reoxygenation-challenged sickle cell disease mice}

To test the effect of long-term oral administration of pyridoxamine on VOC events, SCD mice were given acidic water or pyridoxamine supplemented in drinking water for 5.5 months, starting at 2 weeks after BMT (Figure 4A). Water consumption was equivalent between the two groups, and long-term treatment with pyridoxamine did not influence body weight, the number of $\mathrm{RBC}$ or leukocytes, hematocrit, or the amount of $\mathrm{Hb}$ (Online Supplementary Figure S2A-E). Although in a normal range, platelet counts were significantly lower in SCD mice drinking pyridoxamine-containing water, compared to the control, during the first 2-2.5 months (Online Supplementary Figure S2F), and there was no difference in numbers between the two groups thereafter. Also, there was no difference in urine osmolality between the two groups (Online Supplementary Figure S3). As assessed by intravital microscopy, compared to the control, long-term treatment with pyridoxamine significantly increased the rolling influx and velocity of neutrophils and decreased the number of adherent neutrophils on the inflamed venules in TNF- $\alpha$-challenged SCD mice (Figure 4B-D). Platelet-neutrophil interactions were also slightly reduced with pyridoxamine treatment (Figure 4E). Compared to the control, long-term treatment with pyridoxamine improved the survival of TNF$\alpha$-challenged SCD mice $(P=0.063)$ (Figure $4 \mathrm{~F})$. The median survival time for mice treated with acidic water and pyridoxamine-containing water was 5.3 and $6 \mathrm{~h}$ after TNF- $\alpha$ injection, respectively.

Endothelial dysfunction, activated coagulation, and proinflammatory conditions contribute to organ damage in SCD. ${ }^{1}$ To assess the preventive effect of long-term treatment with pyridoxamine on tissue damage, liver, spleen, and kidney were obtained from SCD mice after intravital microscopy. There was no noticeable organ damage in unchallenged or TNF- $\alpha$-challenged SCD mice treated with acidic water or pyridoxamine-containing water for 5.5 months after BMT (Figure $4 \mathrm{G}$ and $\mathrm{H}$ ). This may result from the age of SCD mice (6-7 months after BMT) since a recent paper shows that severe organ damage in SCD mice is detected 12 months after BMT. ${ }^{34}$ Nevertheless, TNF- $\alpha$-enhanced leukocyte recruitment to the hepatic vessel wall was significantly reduced by long-term treatment of SCD mice with pyridoxamine (Figure 4I).

When intravital microscopy was performed in $\mathrm{H} / \mathrm{R}$ challenged SCD mice, long-term treatment with pyridoxamine exhibited a significant increase in the rolling influx of neutrophils and a decrease in neutrophil adhesion to the venule wall when compared to the control (Online Supplementary Figure S4A and B). However, there was no difference in the number of platelets adherent to neutrophils and $\mathrm{EC}$ or in the percentage of $\mathrm{RBC}$ sickling induced by $\mathrm{H} / \mathrm{R}$ challenge between the two groups (Online Supplementary Figure S4C and D). These results suggest that long-term treatment with pyridoxamine, like short-term treatment, reduces neutrophil adhesiveness in TNF- $\alpha$ - or H/R-challenged SCD mice. 
Long-term treatment with pyridoxamine down-regulates the expression of E-selectin and ICAM-1 on endothelial cell and reduces the surface amount of $\alpha M \beta 2$ integrin on activated neutrophils

To determine whether long-term treatment with pyridoxamine affects the expression of EC E-selectin and ICAM-1 and their levels in circulation, immunohistochemistry was conducted using the cremaster muscle and an enzyme-linked immunosorbent assay was performed with the plasma from TNF- $\alpha$-challenged SCD mice after intravital microscopy. We found that the expression of E-selectin and ICAM-1 was slightly but significantly down-regulated on the vascular endothelium in SCD mice drinking pyridoxamine-containing water compared to those drinking the control water (Figure 5A-C). However, long-term treatment with pyridoxamine did not affect the levels of soluble E-selectin and ICAM-1 in SCD mice (Figure 5D and E). In addition, the plasma levels of IL-1 $\beta$ and IL- 6 were not reduced by long-term treatment with pyridoxamine (Figure $5 \mathrm{~F}$ and $\mathrm{G}$ ).

We further tested whether long-term treatment with pyridoxamine alters the activation state of neutrophils in SCD mice. Neutrophils were isolated from female SCD mice treated with control or pyridoxamine-containing water, followed by flow cytometry to assess activation markers, including membrane translocation of $\alpha \mathrm{M} \beta 2$ inte-
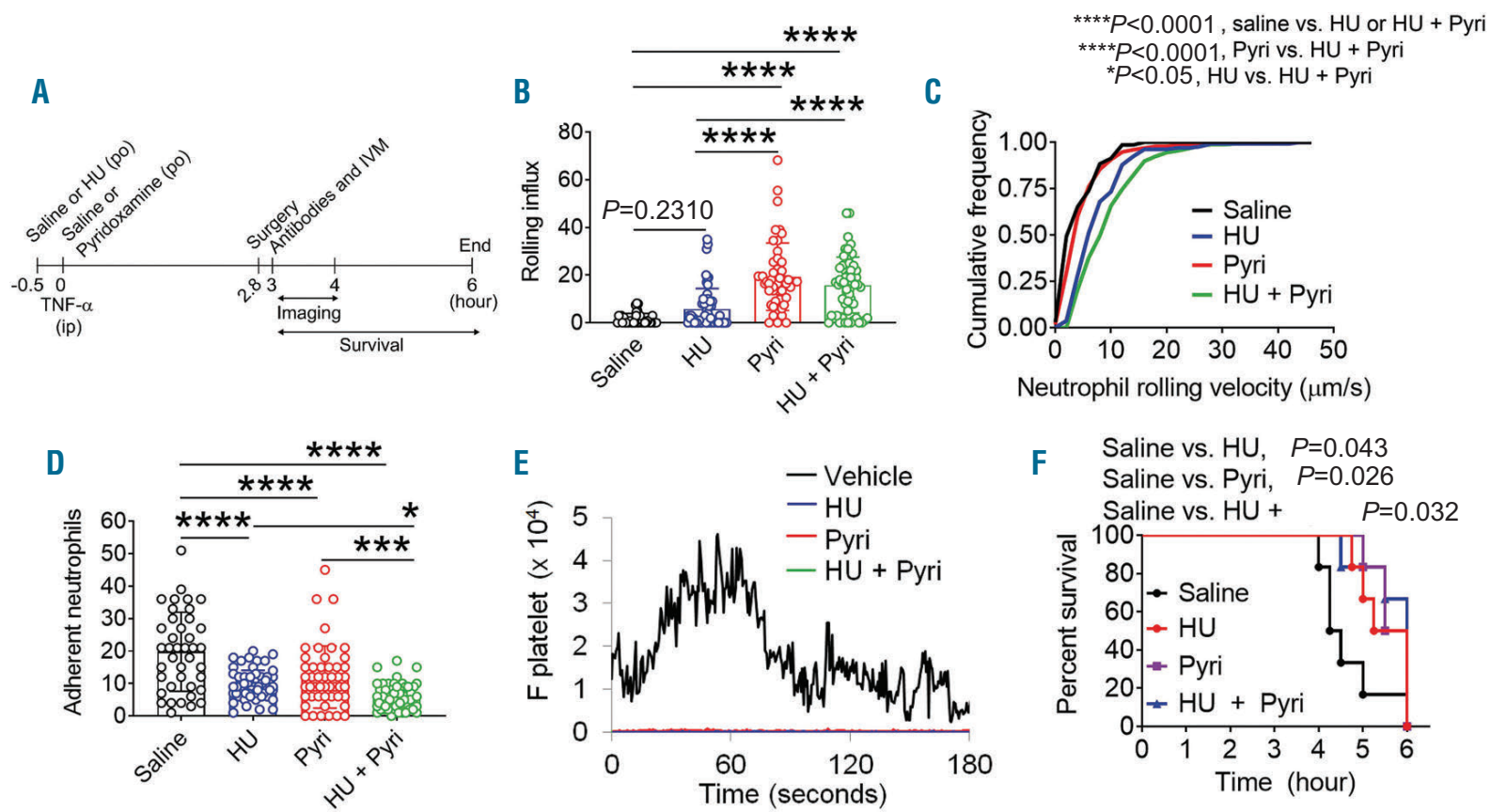

G

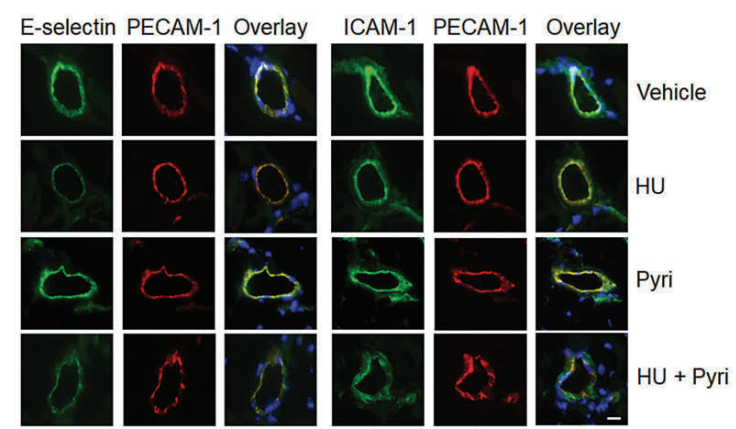

H

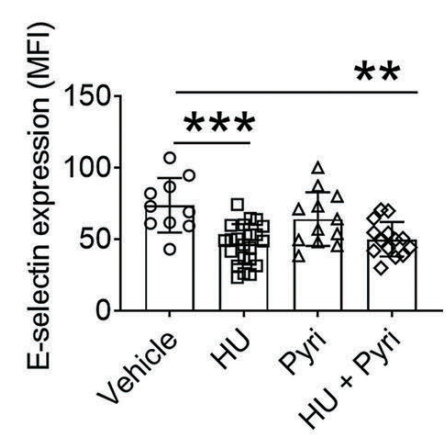

I

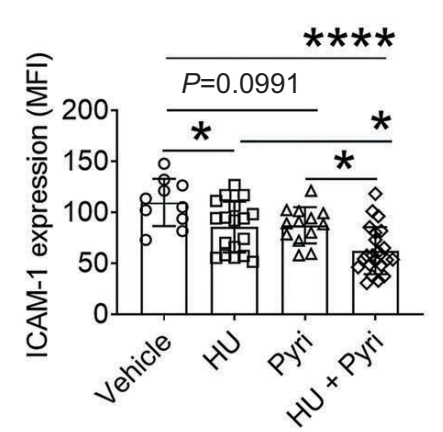

J

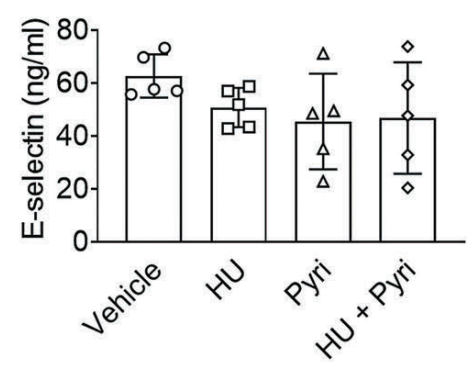

K

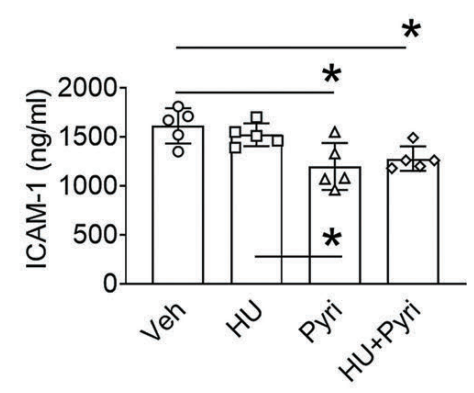


$\mathbf{L}$

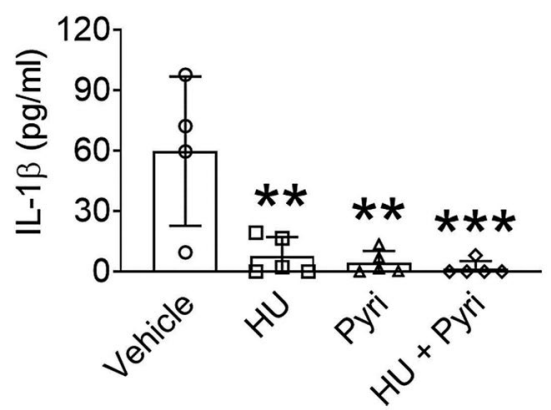

M

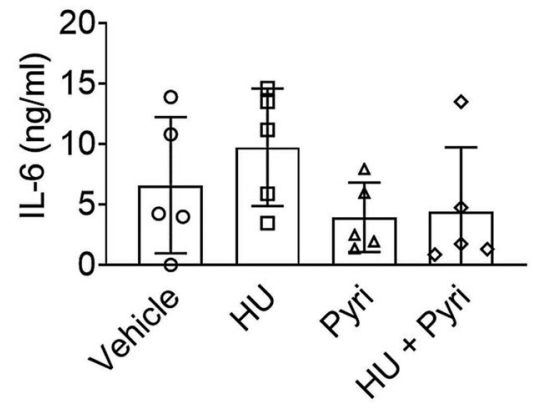

Figure 3 (previous page). Coadministration of hydroxyurea (HU) and pyridoxamine effectively inhibits intravascular cell-cell interactions in the venules and improves the surviva of tumor necrosis factor (TNF)- $\alpha$-challenged sickle cell disease (SCD) mice. Intravital microscopy with TNF- $\alpha$-challenged SCD mice was performed as described in Figure 2. (A) Timeline for HU (250 mg/kg BW) and pyridoxamine (100 mg/kg BW) treatment, TNF- $\alpha$ injection, imaging, and recording survival times. (B) Number of rolling neutrophils. (C) Cumulative frequency of the rolling velocity of neutrophils. (D) Number of adherent neutrophils. (E) Integrated median fluorescence intensity values of anti-CD42c antibodies (F platelets) were plotted over time. (F) Survival curves of SCD mice during or after intravital microscopy. Data represent the mean \pm standard deviation (SD) ( $n=40-59$ venules in 7-8 mice per group). (GI) Following intravital microscopy, the cremaster muscle was taken and fixed for immunohistochemistry. Sections of the muscle were stained for E-selectin, ICAM-1 and PECAM-1. Blue: DAPI. (G) Representative images. Bar $=10 \mu \mathrm{m}$. (H and I) Mean fluorescence intensity (MFI) values of E-selectin and ICAM-1 expression ( $n=10-19$ venules in 3-4 mice per group). (J-M) Levels of E-selectin, ICAM-1, IL-1 $\beta$, and IL-6 were measured in the plasma isolated from SCD mice after recording survival times. Data represent the mean \pm SD $* P<0.05, * * P<0.01$, $* * * P<0.001$, and $* * * * P<0.0001$, ANOVA with Tukey's test (B, D, H-M), Kruskal-Wallis test with post-hoc Dunn correction (C), and Mantel-Cox log-rank test (F).

grin, L-selectin shedding, and reactive oxygen species (ROS) production ${ }^{6,35}$ Compared to the control group, pyridoxamine treatment significantly decreased the surface amount of $\alpha \mathrm{M} \beta 2$ integrin, a receptor required for the interaction of neutrophils with EC and platelets, after agonist stimulation, whereas it did not affect L-selectin shedding and ROS production (Figure 5H-J). These results imply that pyridoxamine attenuates degranulation of $\alpha M \beta 2$ integrin from activated neutrophils, reducing cell adhesiveness.

Long-term treatment with pyridoxamine does not affect the plasma levels of advanced glycation end products and nitric oxide

It is reported that pyridoxamine inhibits AGE formation and scavenges ROS. ${ }^{13,14}$ To measure the plasma levels of AGE, we isolated the plasma from TNF- $\alpha$-challenged male SCD mice after intravital microscopy and from female SCD mice treated with control or pyridoxaminecontaining water. We found that pyridoxamine treatment did not affect the plasma AGE levels between male and female mice and no difference was observed between SCD and non-transplanted Berkeley mice ( $\mathrm{Hbb}^{-/}$, 6-7 months old) and between hemizygous control $\left(\mathrm{Hbb}^{+/}\right)$ and non-transplanted Berkeley mice (Figure 5K). These results suggest that the inhibitory effects of pyridoxamine are not caused by the inhibition of AGE formation in SCD mice.

Enhanced oxidative stress reduces $\mathrm{NO}$ availability and is a key trigger to induce tissue damage in SCD patients. ${ }^{1}$ Thus, we measured the plasma level of nitrites/nitrates (NOx) in SCD mice after long-term treatment with pyridoxamine. Compared with the control mice, pyridoxamine-treated SCD mice did not enhance NOx levels (Figure $5 \mathrm{~L})$. We observed that the NOx levels in SCD mice were significantly higher than hemizygous control and Berkeley mice. ${ }^{20}$ These results suggest that the beneficial effects of pyridoxamine is not derived from scavenging ROS and imply that the result of NOx levels in SCD mice should be interpreted with caution.
Pyridoxamine reduces the activation state of platelets and neutrophils from sickle cell disease mice and patients in vitro

To test whether pyridoxamine affects platelet adhesive function, we performed an in vitro aggregation assay with platelets isolated from SCD mice. Compared to the vehicle control, treatment of platelets with $1 \mathrm{mM}$ pyridoxamine significantly inhibited aggregation and adenosine triphosphate (ATP) secretion induced by thrombin or a collagenrelated peptide (CRP), a glycoprotein VI-specific agonist (Figure 6A-D). Similar inhibitory effects were observed in platelets isolated from WT mice (Online Supplementary Figure S5A and B). As a control, vitamin B6 did not display any inhibitory effect (Online Supplementary Figure S5C and $D)$. We found that compared to vehicle and vitamin B6, treatment of SCD mouse platelets with pyridoxamine inhibited $\alpha I I b \beta 3$ integrin activation and ROS production without affecting P-selectin exposure following thrombin stimulation (Figure 6E-G). Similar results were obtained with WT mouse platelets (Online Supplementary Figure S6). To evaluate the clinical significance of the beneficial effect, we further tested pyridoxamine in platelets from SCD patients. Compared to the vehicle control, pretreatment with $1 \mathrm{mM}$ pyridoxamine significantly inhibited P-selectin exposure and $\alpha \operatorname{Ilb} \beta 3$ activation but not ROS generation in activated platelets (Figure $6 \mathrm{H}-\mathrm{J}$ ). These results suggest that pyridoxamine reduces the activation state and adhesive function of platelets in SCD. The different inhibitory effects in SCD mouse and human platelets, however, remain to be determined.

We then tested whether pyridoxamine treatment affects neutrophil activation. Consistent with the results from the ex vivo studies (Figure $5 \mathrm{H}$ ), pretreatment of SCD mouse neutrophils with $1 \mathrm{mM}$ pyridoxamine reduced the surface amount of $\alpha M \beta 2$ integrin after fMLP stimulation compared with vehicle and vitamin B6 controls (Figure 6K). Lselectin shedding on activated neutrophils was inhibited by both pyridoxamine and vitamin B6 as compared with the vehicle control (Figure $6 \mathrm{~L}$ ). However, ROS production during neutrophil activation was not affected by pyridox- 
amine (Figure 6M). In contrast, pretreatment of neutrophils isolated from SCD patients with pyridoxamine, compared to the vehicle control, reduced ROS generation but did not affect the surface amount of $\alpha \mathrm{M} \beta 2$ and L-selectin following agonist stimulation (Figure 6N-P). Although the different effect of pyridoxamine in mouse and human neutrophils should be further investigated, these results suggest that pyridoxamine reduces neutrophil activation in SCD.

\section{Discussion}

Intravascular cell-cell aggregation directly contribute to
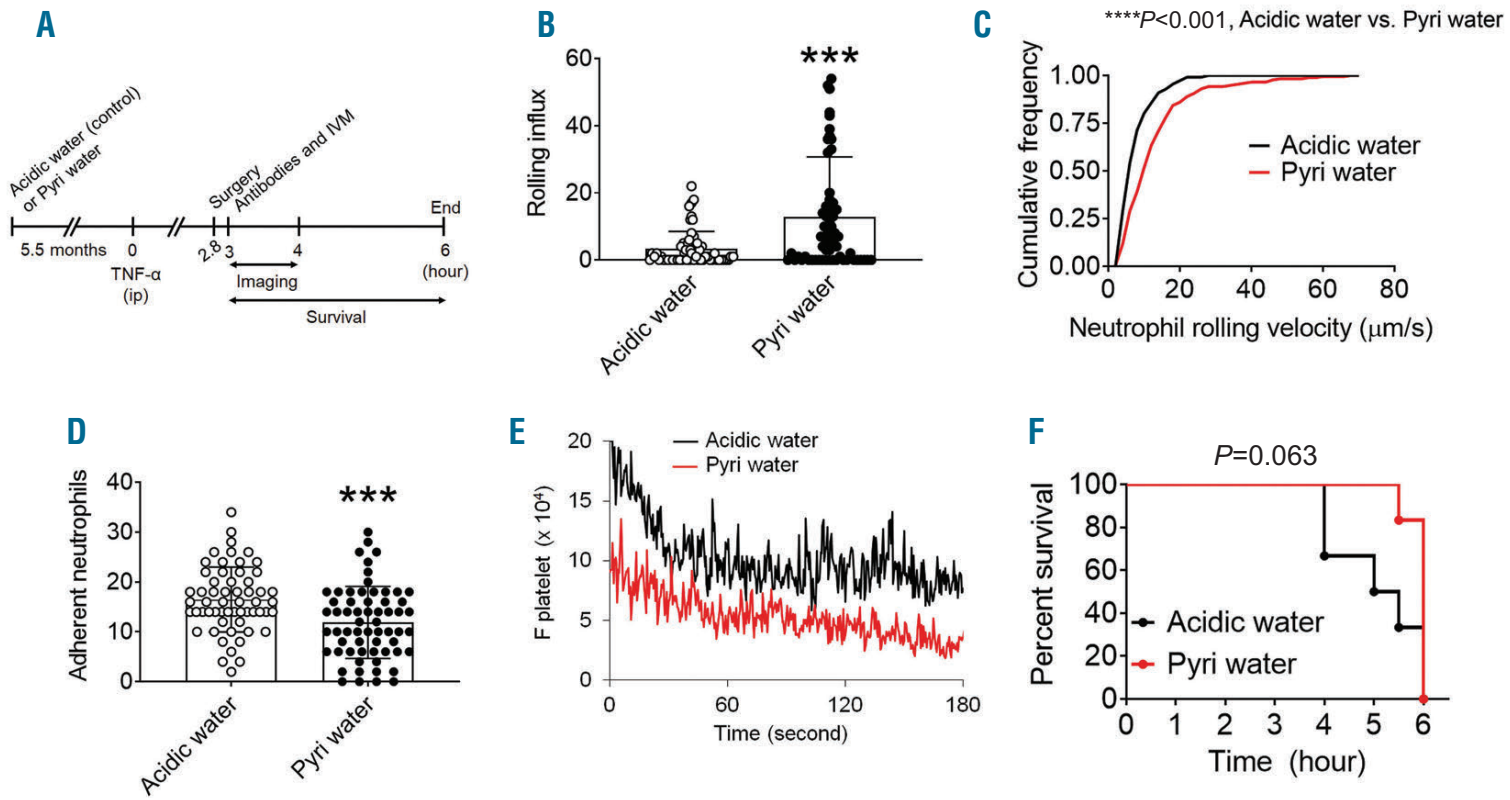

G
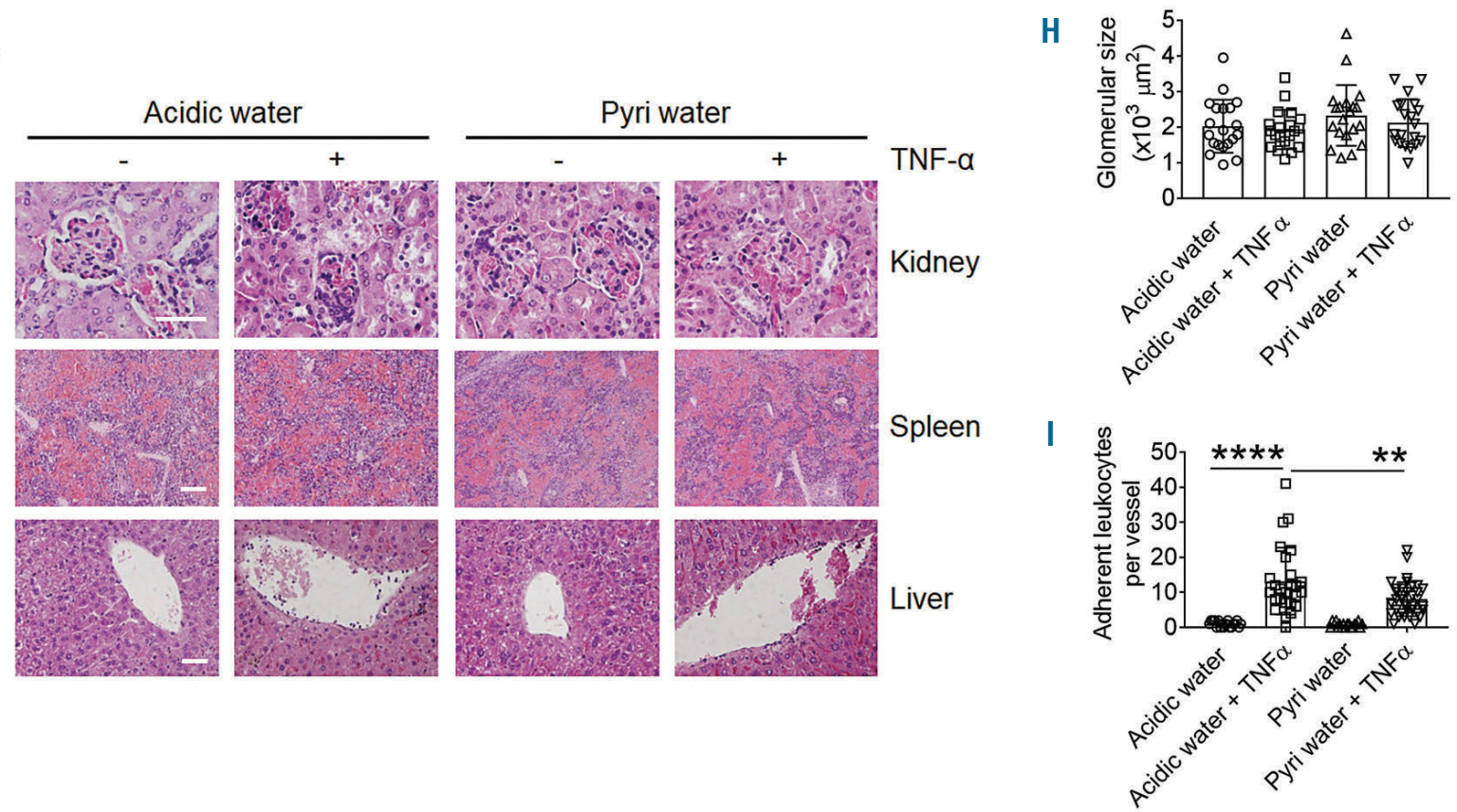

\footnotetext{
Figure 4. Long-term treatment with pyridoxamine impairs neutrophil adhesive function in venules of tumor necrosis factor (TNF)- $\alpha$-challenged sickle cell disease (SCD) mice. Male (A-P and T-U) and female (Q-U) SCD mice were given acidic water or pyridoxamine (2 g/L) in the drinking water, starting at 2 weeks after bone marrow transplantation and continued for 5.5 months. Intravital microscopy with TNF- $\alpha$-challenged SCD mice was performed as described in Figure 2. (A) Timeline for the treatment with acidic or pyridoxamine-containing water, TNF- $\alpha$ injection, imaging, and recording survival times. (B) Rolling influx of neutrophils. (C) Cumulative frequency of the rolling velocity of neutrophils. (D) Number of adherent neutrophils. (E) Integrated median fluorescence intensity values of anti-CD42C antibodies ( $F$ platelets) were plotted over time. (F) Survival curves of SCD mice during or after intravital microscopy. Data represent the mean \pm Standard deviation (SD) ( $\mathrm{n}=58-62$ venules in 7-8 mice per group). (G-I) Kidney, spleen, and liver were obtained from unchallenged or TNF- $\alpha$-challenged SCD mice treated with acidic water or pyridoxamine-containing water after recording the survival time. (G) Representative hematoxylin and eosin staining. Bar=50 um. (H) Glomerular size. (I) Number of adherent leukocytes on the hepatic vessel wall. Data represent the mean $\pm \mathrm{SD}(\mathrm{n}=7$ mice per group). $* * P<0.01, * * * P<0.001$, and $* * * * P<0.0001, \mathrm{Student}$ 's $t$-test $(\mathrm{B}, \mathrm{D}, \mathrm{H}$, and I), Mann-Whitney U test (C), and Mantel-Cox log-rank test (F).
} 
VOC in SCD. ${ }^{20,25,36,37}$ In this study, we demonstrate that short- and long-term oral administration of pyridoxamine significantly reduces intravascular cell-cell interactions in the microvessels of $\mathrm{H} / \mathrm{R}$ - or TNF- $\alpha$-challenged SCD mice and improves survival. The beneficial effects are enhanced when pyridoxamine is co-administered with HU. Mechanistically, pyridoxamine reduces the activation state of neutrophils and platelets from SCD mice and patients. These results suggest that pyridoxamine might be repurposed to prevent and treat acute VOC events in SCD. Nevertheless, we are aware that although statistically significant, the inhibitory effect of pyridoxamine itself on cell-cell interactions is weak to moderate after shortand long-term treatment in SCD mice. Therefore, its effi-
A

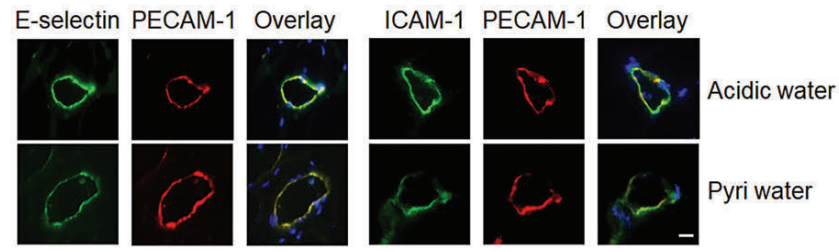

B
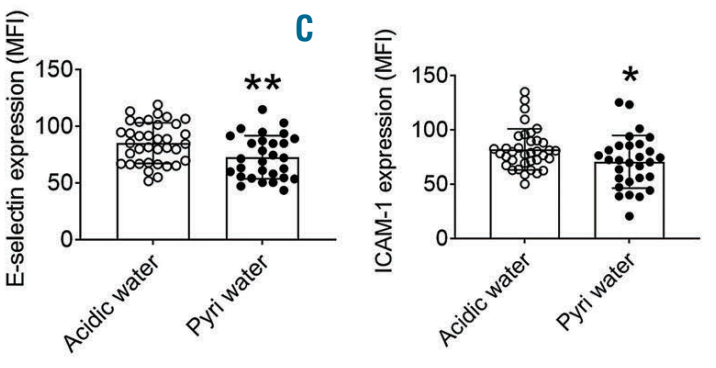

D

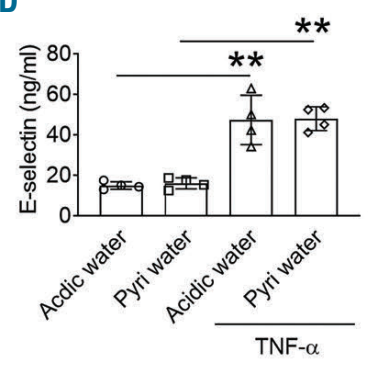

F

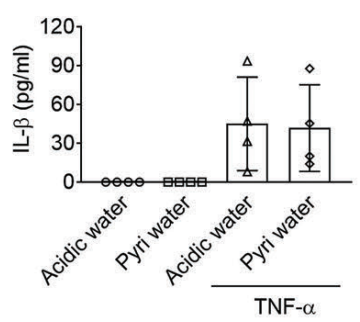

E

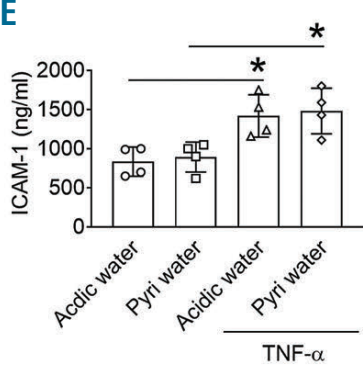

G

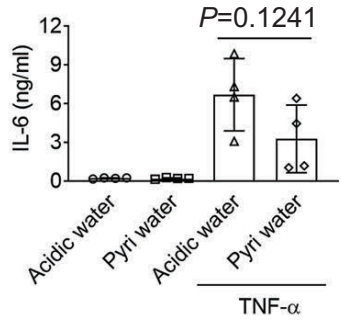

H

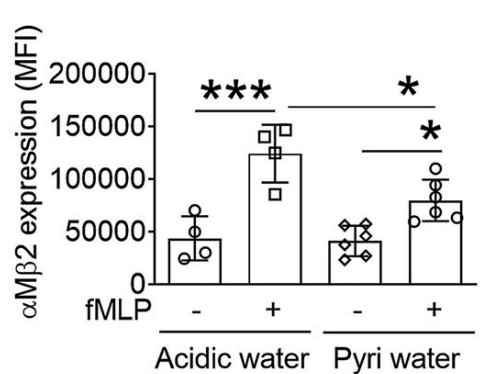

K

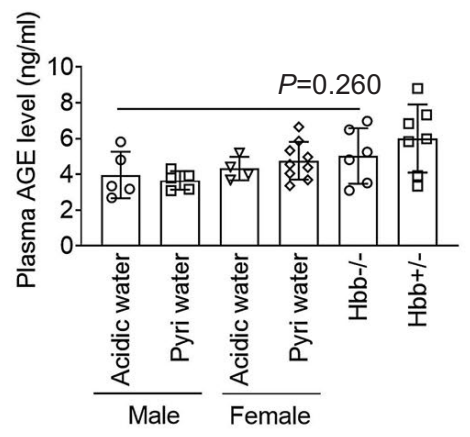

I

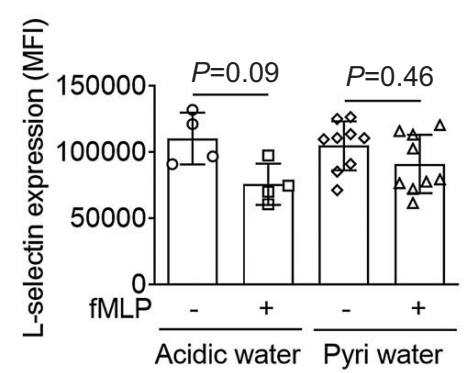

L

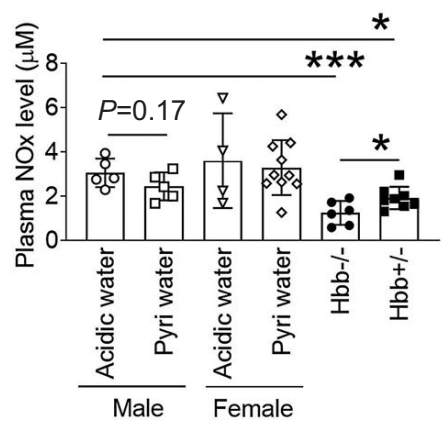

J

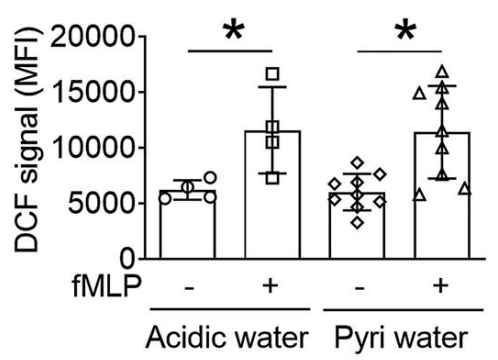

Figure 5. Long-term treatment with pyridoxamine reduces the expression of E-selectin and ICAM-1 on endothelial cells (EC) and decreases the surface amount of neutrophil $\alpha \mathrm{M} \beta 2$ integrin. (A-C) Immunihistochemistry was performed as described in Figure 3 . Bar $=10 \mu \mathrm{m}$. Data represent the mean \pm standard deviation (SD) $(n=29-36$ venules in 5 mice per group). (D-G) Levels of E-selectin, ICAM-1, IL-1 $\beta$, and IL-6 were measured in the plasma from SCD mice after recording the survival time. (H-J) Neutrophils were isolated from female SCD mice treated with control or pyridoxamine-containing water. Surface amounts of $\alpha \mathrm{M} \beta 2$ integrin and L-selectin and ROS generation were assessed by flow cytometry. (K-L) Plasma was isolated from TNF- $\alpha$-challenged male SCD mice after intravital microscopy and from female SCD mice treated with control or pyridoxamine-containing water. $\mathrm{Hbb}^{/ \%}$ : non-transplanted Berkeley mouse; $\mathrm{Hbb}^{+/}$: hemizygous control. Plasma levels of advanced glycation end products (AGE) and nitrogen oxides (NOx) were measured as described in the Methods section. Data represent the mean $\pm S D$ ( $n=4-9$ mice per group). $* P<0.05, * * P<0.01$, and $* * * P<0.001$, Student's $t$-test (B-G) and ANOVA with Tukey's test $(\mathrm{H}-\mathrm{L})$. 
A

$0.05 \mathrm{U} / \mathrm{ml}$ thrombin
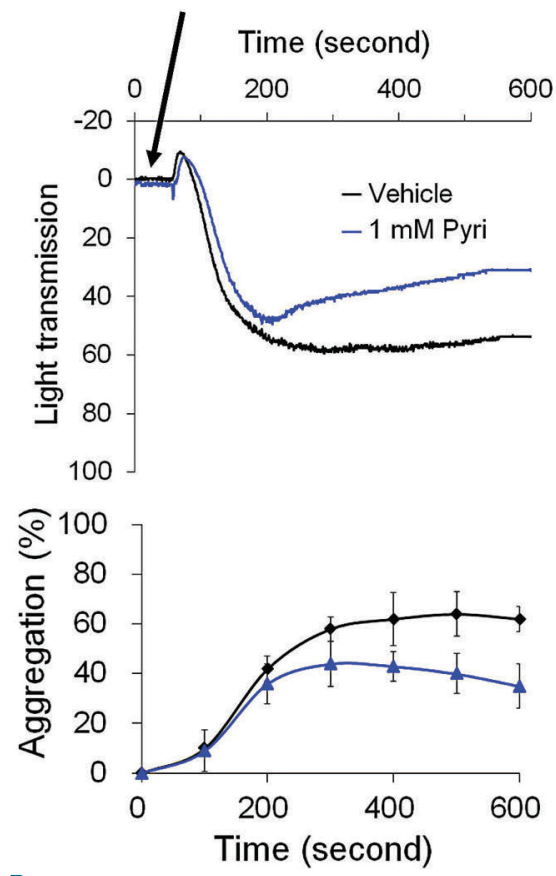

B

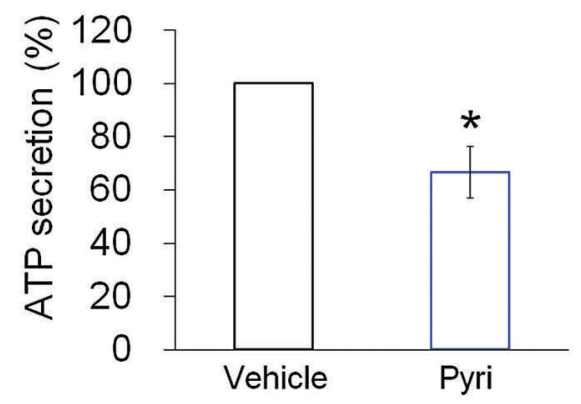

C
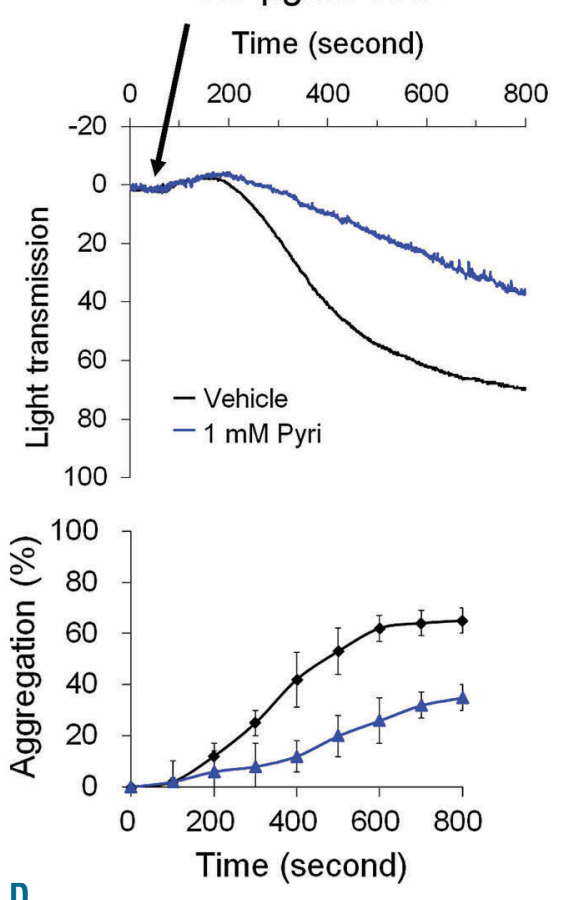

D

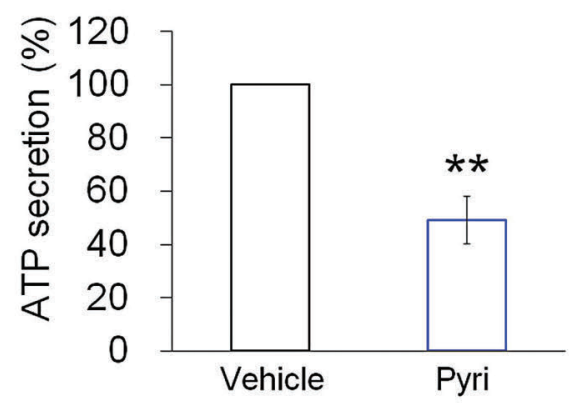

E

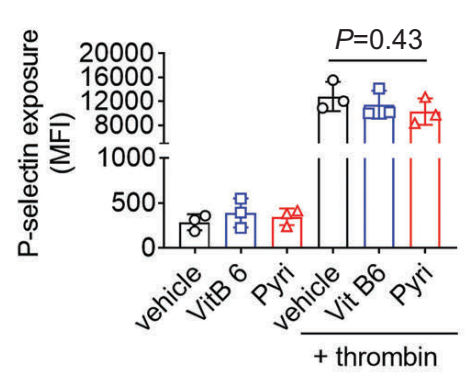

H

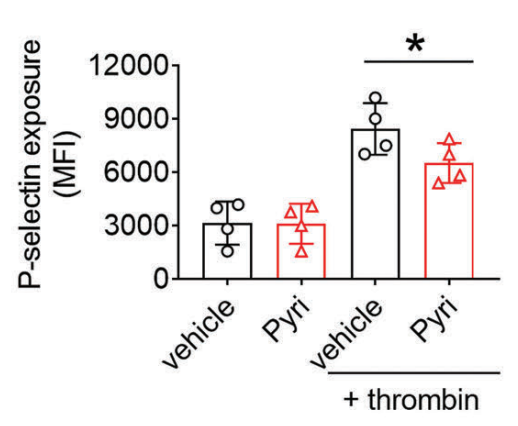

F
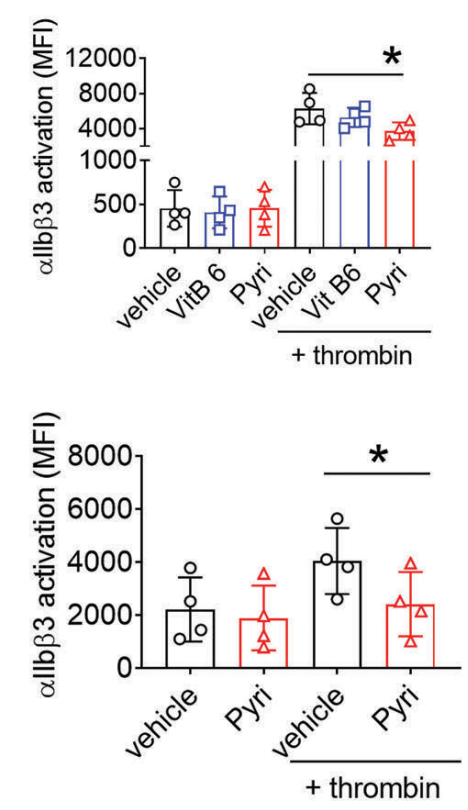

G

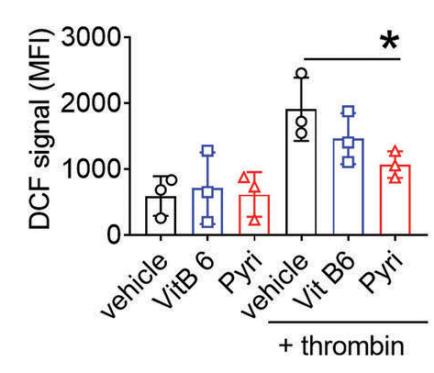

J

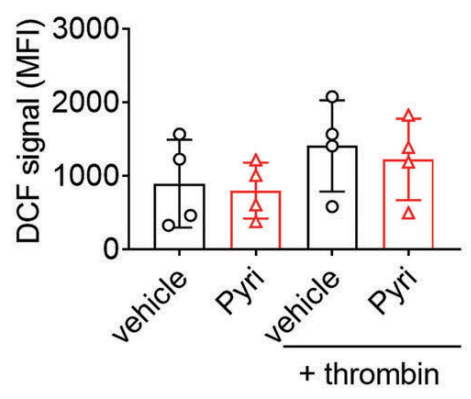


K

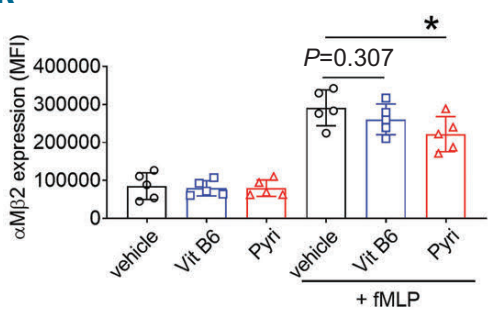

N

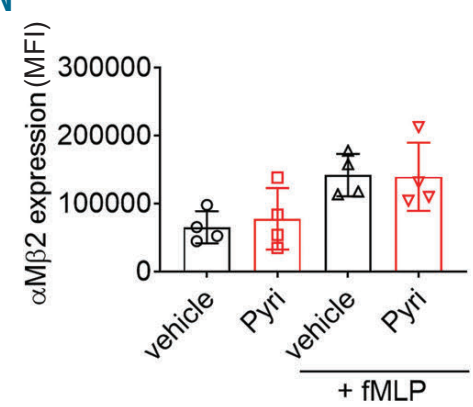

L

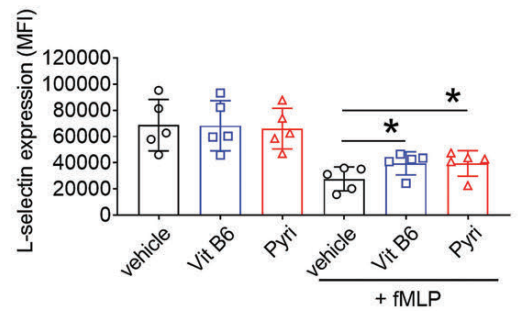

0

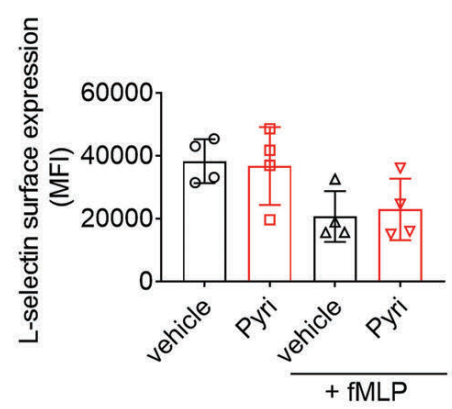

M

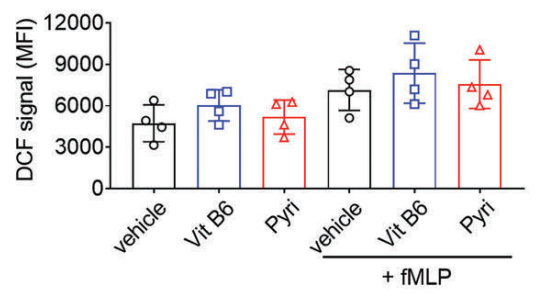

P

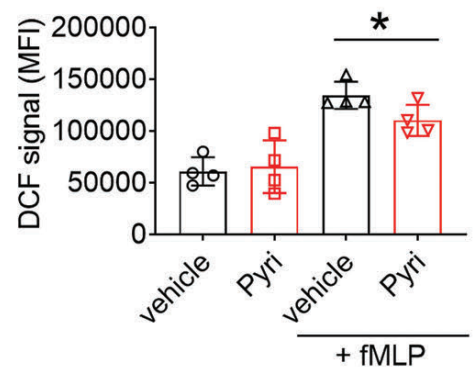

Figure 6 (previous page). Pyridoxamine treatment inhibits the activation state of platelets and neutrophils isolated from sickle cell disease (SCD) mice and patients. Platelets isolated from SCD mice (A-G) and patients $(\mathrm{H}-\mathrm{J})$ were pretreated with $1 \mathrm{mM}$ pyridoxamine, followed by stimulation with $0.05 \mathrm{U} / \mathrm{mL}$ thrombin or 3.5 $\mu \mathrm{g} / \mathrm{mL}$ collagen related peptide. (A and C) Representative traces of platelet aggregation and quantitative graphs. (B and D) Adenosine triphosphate secretion was monitored with a luciferin/luciferase reagent and are shown as \% of control at the end of the time point. (E-J) Flow cytometry was performed to assess P-selectin exposure, $\alpha$ llb $\beta 3$ activation and reactive oxygen species (ROS) generation. Neutrophils isolated from SCD mice (K-M) and patients (N-P) were pretreated with 1 mM pyridoxamine, followed by incubation with fMLP. Flow cytometry was carried out to determine the surface amounts of $\alpha \mathrm{M} \beta 2$ and L-selectin and ROS production. Data represent the mean \pm standard deviation $(n=3-5)$. $* P<0.05$ and $* * P<0.01$ versus vehicle control, Student's $t$-test.

cacy should be carefully tested in a future study with SCD patients.

Although short-term pyridoxamine treatment significantly increases the rolling influx of neutrophils in H/R- or TNF- $\alpha$-challenged SCD mice, the rolling velocity of neutrophils was faster in $\mathrm{H} / \mathrm{R}$ - but not in TNF- $\alpha$-challenged mice with pyridoxamine treatment (Figures 1 and 3 ). This discrepancy might result from the difference in severity of the inflammatory conditions between the two models. Since our in vivo studies used (transplanted) SCD mice that would be less inflammatory compared to (non-transplanted) Berkeley mice with lifelong inflammation, the TNF- $\alpha$ model may better represent the inflammatory condition in SCD. Furthermore, our finding that short-term treatment with pyridoxamine does not affect E-selectin expression but inhibits ICAM-1 expression on the TNF- $\alpha$-inflamed venular wall (Figure 3G-I) implies that pyridoxamine treatment increases neutrophil rolling due to decreased adhesiveness on EC. It should be noted that co-administration of pyridoxamine and $\mathrm{HU}$ enhances the inhibitory effect of each drug on the adhesive function of neutrophils. HU exhibits its clinical benefit through multiple mechanisms, including inducing $\mathrm{HbF}$ production, lowering the number of circulating leukocytes and reticulocytes, increasing $\mathrm{NO}$ production, and reducing phosphatidylserine exposure. ${ }^{38,39}$ Given the synergistic effect, pyridoxamine is likely to act distinctly from HU without compromising the beneficial effect, providing evidence that pyridoxamine could be a supplement to HU therapy for patients with SCD.

After oral administration, pyridoxamine is converted to other forms of vitamin B6, including pyridoxal phosphate, ${ }^{40,41}$ which has been reported to inhibit platelet function. ${ }^{42}$ However, there is a limit to the conversion of pyridoxamine to other forms of vitamin B6. For example, when 40-140 nmol of pyridoxamine was given to mice, the major B6 vitamer in the blood ( $>40 \%$ ) was pyridoxamine itself. ${ }^{40,41}$ Since the saturation doses used in the pharmacokinetic studies are significantly lower than the doses used in our in vivo study (10-100 mg/kg BW, approximately 1-10 $\mu \mathrm{mol}$ per $25 \mathrm{~g}$ mouse), the dose-dependent effects (Figure 1) are likely due to increasing concentrations of pyridoxamine rather than other vitamin B6 derivatives.

Pyridoxamine can trap reactive carboxyl intermediates that lead to the formation of AGE, which contribute to the pathophysiology of retinal and renal lesions in diabetes. ${ }^{43}$ Previous studies demonstrated that pyridoxamine inhibits the progression of diabetic nephropathy in mice and rats. ${ }^{15,44,45}$ In support of the preclinical studies, a phase II study with patients with type $1 / 2$ diabetic nephropathy reveals that compared to placebo, oral administration of pyridoxamine (50 or $250 \mathrm{mg}$ ) twice daily for 24 weeks significantly reduces the levels of serum creatinine and urinary TGF- $\beta 1{ }^{17}$ However, another study with patients with proteinuric type 2 diabetic nephropathy shows that pyridoxamine (150 or $300 \mathrm{mg}$ twice daily) does not significantly decrease the concentration of serum creatinine after 1 year of therapy, ${ }^{18}$ making the beneficial effect of pyridoxamine in diabetic nephropathy controversial. Our intravital microscopy with SCD mice demonstrates that long-term treatment with pyridoxamine attenuates neutrophil and platelet adhesive functions and improves mice survival (Figure 4). Although the increased levels of plasma and skin AGE are reported to be associated with oxidative stress and organ complications in SCD patients, ${ }^{19,46}$ our ex vivo studies reveal there is no difference in plasma AGE 
levels between 6-month old hemizygous control and Berkeley mice, and that these remain unchanged after pyridoxamine treatment (Figure 5K). These results imply that the beneficial effects of pyridoxamine in SCD result from a mechanism distinct from inhibiting AGE formation. Furthermore, there were no signs of tissue damage in the liver, kidney, and spleen of SCD mice 6-7 months after BMT. Thus, further studies with older Berkeley and SCD mice are required to investigate the plasma level of AGE and organ damage, and to examine the effect of pyridoxamine.

Previous studies showed that pyridoxamine inhibits platelet aggregation induced by ADP or both collagen and Isoketal. ${ }^{42,8,48}$ However, whether it affects platelet activation remains to be explored. Furthermore, the effect of pyridoxamine on neutrophil function remains unknown. Our studies have shown that pyridoxamine treatment partially impairs the activation state and/or adhesiveness of platelets and neutrophils from SCD mice and patients (Figure 6). Since platelet $\alpha \operatorname{Ilb} \beta 3$ integrin plays a role in platelet-neutrophil interactions in vivo, ${ }^{21}$ decreased $\alpha \operatorname{Ilb} \beta 3$ activation by pyridoxamine in both SCD mouse and human platelets could account for the decreased cell-cell interaction in TNF- $\alpha$-challenged SCD mice (Figures 2-4). In addition, our finding that pyridoxamine treatment reduces the surface amount of neutrophil $\alpha \mathrm{M} \beta 2$ integrin in mouse neutrophils (Figures $5 \mathrm{H}$ and $6 \mathrm{~K}$ ), ${ }^{49}$ is consistent with the impaired platelet-neutrophil interactions in SCD mice (Figures 2-4). Our results suggest that pyridoxamine may block a specific signaling pathway(s) during activation of platelets and neutrophils in SCD. In support of this speculation, we found that pretreatment of platelets and neutrophils isolated from SCD mice with pyridoxamine inhibits phosphorylation of AKT following agonist stimulation (Online Supplementary Figure S7). Nevertheless, we cannot fully explain why pyridoxamine has a different effect on platelets and on neutrophils isolated from SCD patients and mice. It is noteworthy that unlike SCD patients, Berkeley mice do not have mural thrombi, large vessel vasculopathy, cerebral infarcts, or hemorrhagic strokes. ${ }^{50}$ These results suggest that compared to patients, SCD mice are less inflammatory and their blood cells might be less activated. Therefore, the different activation state of blood cells might influence the pyridoxamine effect. Furthermore, a different source of neutrophils used in this study (blood neutrophils from patients vs. bone marrow neutrophils from mice) might be the reason for the discrepancy.

Drugs targeting the activation and adhesion of leukocytes and platelets, coagulation, and inflammation are being tested in clinical studies on the prevention and treatment of VOC-mediated pain crises in SCD patients. ${ }^{1,51}$ In recent phase II studies, the leading drugs, rivipansel and crizanlizumab, were reported to reduce time to resolution of $\mathrm{VOC}$ events and requirement for opioid analgesia in SCD patients. ${ }^{9,10}$ However, complete inhibition of leukocyte-EC contacts might disrupt the innate immune response. For this reason, the phase II clinical trial of rivapansel excluded patients with fever. ${ }^{10}$ Our results demonstrate the inhibitory effects of short- and long-term treatment with pyridoxamine on the adhesive function of neutrophils and platelets in the microvessels of SCD mice. Since previous clinical studies have shown no or minimal adverse events of pyridoxamine in patients with diabetic nephropathy, ${ }^{17,18}$ our results suggest that further investigations into the use of pyridoxamine to prevent and treat acute VOC-mediated crises in SCD patients undergoing HU therapy are warranted.

\section{Funding}

This work was supported by (R01HL130028, R01HL148280, and R43HL142402) and the University of Illinois at Chicago Center for Clinical and Translational Science award UL1TR002003. JL is a recipient of American Heart Association Career Development Award. BX is a recipient of a scholarship from the China Scholarship Council. AT is a recipient of NIH Ruth L. Kirschstein National Research Service Award Individual Predoctoral Fellowship (F3OHL134296).

\section{References}

1. Zhang D, Xu C, Manwani D, Frenette PS. Neutrophils, platelets, and inflammatory pathways at the nexus of sickle cell disease pathophysiology. Blood. 2016;127(7):801809.

2. Paul RN, Castro OL, Aggarwal A, Oneal PA. Acute chest syndrome: sickle cell disease. Eur J Haematol. 2011;87(3):191-207.

3. Rodgers GP, Dover GJ, Noguchi CT, Schechter AN, Nienhuis AW. Hematologic responses of patients with sickle cell disease to treatment with hydroxyurea. $\mathrm{N}$ Engl J Med. 1990;322(15):1037-1045.

4. Steinberg MH, Lu ZH, Barton FB, et al. Fetal hemoglobin in sickle cell anemia: determinants of response to hydroxyurea. Blood. 1997;89(3):1078-1088.

5. Niihara Y, Miller ST, Kanter J, et al. A Phase 3 trial of l-glutamine in sickle cell disease. N Engl J Med. 2018;379(3):226-235.

6. Li J, Kim K, Hahm E, et al. Neutrophil AKT2 regulates heterotypic cell-cell interactions during vascular inflammation. J Clin Invest. 2014;124(4):1483-1496.

7. Belcher JD, Chen C, Nguyen J, et al. The fucosylation inhibitor, 2-fluorofucose, inhibits vaso-occlusion, leukocyteendothelium interactions and NF-kB activation in transgenic sickle mice. PLoS One. 2015;10(2):e0117772.

8. Zhang D, Chen G, Manwani D, et al. Neutrophil ageing is regulated by the microbiome. Nature. 2015;525(7570):528-532.

9. Ataga KI, Kutlar A, Kanter J, et al. Crizanlizumab for the prevention of pain crises in sickle cell disease. N Engl J Med. 2017;376(5):429-439.

10. Telen MJ, Wun T, McCavit TL, et al. Randomized phase 2 study of GMI-1070 in SCD: reduction in time to resolution of vaso-occlusive events and decreased opioid use. Blood. 2015;125(17):2656-2664.

11. Heeney MM, Hoppe CC, Abboud MR, et al. A Multinational Trial of Prasugrel for sickle cell vaso-occlusive Events. N Engl J Med. 2016;374(7):625-635.

12. Becker RC, Sexton T, Smyth SS. Translational Implications of Platelets as Vascular First Responders. Circ Res. 2018; 122(3):506-522.

13. Onorato JM, Jenkins AJ, Thorpe SR, Baynes JW. Pyridoxamine, an inhibitor of advanced glycation reactions, also inhibits advanced lipoxidation reactions. Mechanism of action of pyridoxamine. J Biol Chem. 2000;
275(28):21177-21184

14. Voziyan PA, Khalifah RG, Thibaudeau C, et al. Modification of proteins in vitro by physiological levels of glucose: pyridoxamine inhibits conversion of Amadori intermediate to advanced glycation end-products through binding of redox metal ions. J Biol Chem. 2003;278(47):46616-46624.

15. Degenhardt TP, Alderson NL, Arrington DD, et al. Pyridoxamine inhibits early renal disease and dyslipidemia in the streptozotocindiabetic rat. Kidney Int. 2002; 61(3):939-950.

16. Ozer A, Altuntas CZ, Izgi K, et al Advanced glycation end products facilitate bacterial adherence in urinary tract infection in diabetic mice. Pathog Dis. 2015;73(5).

17. Williams ME, Bolton WK, Khalifah RG, et al. Effects of pyridoxamine in combined phase 2 studies of patients with type 1 and type 2 diabetes and overt nephropathy. Am J Nephrol. 2007;27(6):605-614.

18. Lewis EJ, Greene T, Spitalewiz S, et al. Pyridorin in type 2 diabetic nephropathy. J Am Soc Nephrol. 2012;23(1):131-136.

19. Nur E, Brandjes DP, Schnog JJ, et al. Plasma levels of advanced glycation end products are associated with haemolysis-related organ complications in sickle cell patients. 
Br J Haematol. 2010;151(1):62-69.

20. Barazia A, Li J, Kim K, Shabrani N, Cho J. Hydroxyurea with AKT2 inhibition decreases vaso-occlusive events in sickle cell disease mice. Blood. 2015;126(22): 2511-2517.

21. Li J, Kim K, Jeong SY, et al. Platelet protein disulfide isomerase promotes glycoprotein Ib $\alpha$-mediated platelet-neutrophil interactions under thromboinflammatory conditions. Circulation. 2019;139(10):1300-1319.

22. Murakoshi M, Tanimoto M, Gohda T, et al. Pleiotropic effect of pyridoxamine on diabetic complications via CD36 expression in KK-Ay/Ta mice. Diabetes Res Clin Pract. 2009;83(2):183-189.

23. Sun K, Xia Y. New insights into sickle cell disease: a disease of hypoxia. Curr Opin Hematol. 2013;20(3):215-221.

24. Rubin EM, Witkowska HE, Spangler E, et al. Hypoxia-induced in vivo sickling of transgenic mouse red cells. J Clin Invest. 1991;87(2):639-647.

25. Hidalgo A, Chang J, Jang JE, et al. Heterotypic interactions enabled by polarized neutrophil microdomains mediate thromboinflammatory injury. Nat Med. 2009;15(4):384-391.

26. Bennewitz MF, Jimenez MA, Vats $R$, et al. Lung vaso-occlusion in sickle cell disease mediated by arteriolar neutrophil-platelet microemboli. JCI Insight. 2017;2(1): e89761.

27. Polanowska-Grabowska R, Wallace K, Field JJ, et al. P-selectin-mediated plateletneutrophil aggregate formation activates neutrophils in mouse and human sickle cell disease. Arterioscler Thromb Vasc Biol. 2010;30(12):2392-2399.

28. Kim K, Li J, Barazia A, et al. ARQ 092, an orally-available, selective AKT inhibitor, attenuates neutrophil-platelet interactions in sickle cell disease. Haematologica. 2017;102(2):246-259.

29. Li J, Cho J. Ser/Thr protein kinase Bbeta$\mathrm{NADPH}$ oxidase 2 signaling in thromboinflammation. Curr Opin Hematol. 2017; 24(5):460-466.

30. Almeida CB, Scheiermann C, Jang JE, et al. Hydroxyurea and a cGMP-amplifying agent have immediate benefits on acute vaso-occlusive events in sickle cell disease mice. Blood. 2012;120(14):2879-2888.

31. Phillipson M, Kubes P. The neutrophil in vascular inflammation. Nat Med. 2011; 17(11):1381-1390.

32. Kato GJ, Martyr S, Blackwelder WC, et al. Levels of soluble endothelium-derived adhesion molecules in patients with sickle cell disease are associated with pulmonary hypertension, organ dysfunction, and mortality. Br J Haematol. 2005;130(6):943-953.

33. Saleh AW, Duits AJ, Gerbers A, de Vries C, Hillen HF. Cytokines and soluble adhesion molecules in sickle cell anemia patients during hydroxyurea therapy. Acta Haematol. 1998;100(1):26-31.

34. Nasimuzzaman M, Arumugam PI, Mullin $\mathrm{ES}$, et al. Elimination of the fibrinogen integrin $\alpha M \beta 2$-binding motif improves renal pathology in mice with sickle cell anemia. Blood Adv. 2019;3(9):1519-1532.

35. Kim K, Li J, Tseng A, Andrews RK, Cho J. NOX2 is critical for heterotypic neutrophilplatelet interactions during vascular inflammation. Blood. 2015;126(16):1952-1964.

36. Jimenez MA, Novelli E, Shaw GD, Sundd P. Glycoprotein Ibalpha inhibitor (CCP-224) prevents neutrophil-platelet aggregation in sickle cell disease. Blood Adv. 2017; 1(20):1712-1716.

37. Li J, Kim K, Barazia A, Tseng A, Cho J. Platelet-neutrophil interactions under thromboinflammatory conditions. Cell Mol Life Sci. 2015;72(14):2627-2643.

38. Singh PC, Ballas SK. Emerging drugs for sickle cell anemia. Expert Opin Emerg Drugs. 2015;20(1):47-61.

39. Piccin A, Murphy C, Eakins E, et al. Insight into the complex pathophysiology of sickle cell anaemia and possible treatment. Eur J Haematol. 2019:102(4):319-330.

40. Sakurai T, Asakura T, Mizuno A, Matsuda M. Absorption and metabolism of pyridoxamine in mice. I. Pyridoxal as the only form of transport in blood. J Nutr Sci Vitaminol (Tokyo). 1991;37(4):341-348.

41. Sakurai T, Asakura T, Mizuno A, Matsuda M. Absorption and metabolism of pyridoxamine in mice. II. Transformation of pyri- doxamine to pyridoxal in intestinal tissues. J Nutr Sci Vitaminol (Tokyo). 1992, 38(3):227-233.

42. Subbardo K, Kuchibhotla J, Kakkar VV. Pyridoxal 5'-phosphate--a new physiological inhibitor of blood coagulation and platelet function. Biochem Pharmacol. 1979;28(4):531-534.

43. Brownlee M. Advanced protein glycosylation in diabetes and aging. Annu Rev Med. 1995;46:223-234.

44. Alderson NL, Chachich ME, Frizzell N, et al. Effect of antioxidants and ACE inhibition on chemical modification of proteins and progression of nephropathy in the streptozotocin diabetic rat. Diabetologia. 2004;47(8):1385-1395.

45. Zheng F, Zeng YJ, Plati AR, et al. Combined AGE inhibition and ACEi decreases the progression of established diabetic nephropathy in B6 db/db mice. Kidney Int. 2006;70(3):507-514.

46. Kashyap L, Alsaheel A, Ranck M, et al Sickle cell disease is associated with elevated levels of skin advanced glycation endproducts. J Pediatr Hematol Oncol. 2018; 40(4):285-289.

47. Chang SJ, Chang CN, Chen CW Occupancy of glycoprotein IIb/IIIa by B-6 vitamers inhibits human platelet aggregation. J Nutr. 2002;132(12):3603-3606.

48. Bernoud-Hubac N, Alam DA, Lefils J, et al Low concentrations of reactive gammaketoaldehydes prime thromboxane-dependent human platelet aggregation via p38MAPK activation. Biochim Biophys Acta. 2009;1791(4):307-313.

49. Wang $Y$, Sakuma $M$, Chen $Z$, et al Leukocyte engagement of platelet glycoprotein Ibalpha via the integrin Mac-1 is critical for the biological response to vascular injury. Circulation. 2005;112(19):29933000

50. Manci EA, Hillery CA, Bodian CA, et al Pathology of Berkeley sickle cell mice: similarities and differences with human sickle cell disease. Blood. 2006;107(4):1651-1658.

51. Tran H, Gupta M, Gupta K. Targeting novel mechanisms of pain in sickle cell disease. Blood. 2017;130(22):2377-2385. 